\title{
La consolidación de una cita fundamental
}

\author{
Reseña de: GrACIA, J. y Asión, A. (coords.), Nuevas visiones sobre el cómic. Un \\ enfoque interdisciplinar, Zaragoza, Prensas de la Universidad de Zaragoza, 2018
}

Pablo C. Anía Ruiz-Flores

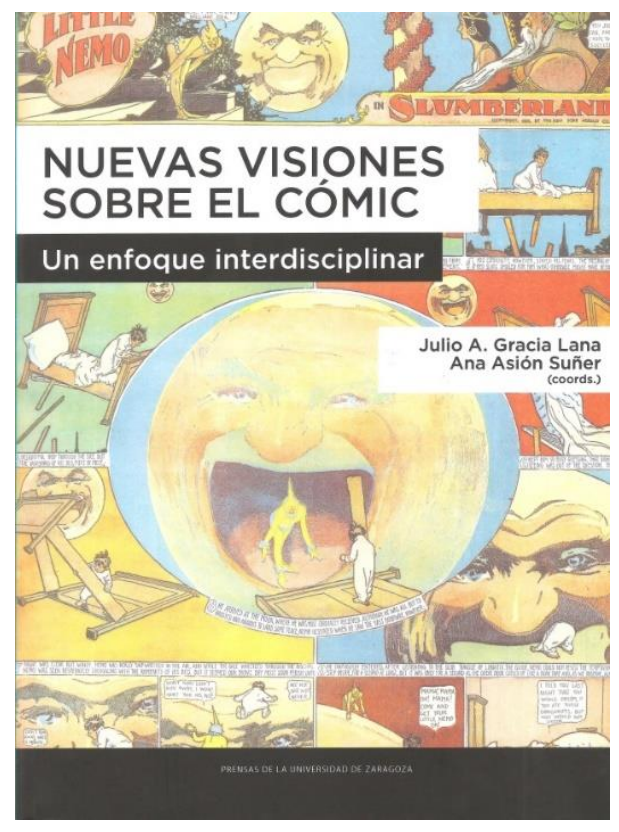

En nuestro país son multitud los investigadores que han dedicado su estudio al campo del cómic. Numerosas han sido las publicaciones que desde principios del siglo XXI han intentado abrirse camino en el mundo académico. Poco a poco este nicho fue aumentando y dando lugar a una mayor demanda y profundidad de los estudios sobre historieta. De esta forma y para dar voz a las diferentes investigaciones que se estaban realizando en la actualidad, nace la publicación Nuevas visiones sobre el cómic. Un enfoque interdisciplinar, ${ }^{1}$ editada por Prensas de la Universidad de Zaragoza. Sin embargo, este manifiesto no solo tiene un valor en sí mismo por la calidad de la publicación y la gran variedad de propuestas que recoge, sino que también es importante por ser el testimonio escrito del I Congreso Internacional de Estudios Interdisciplinares sobre Cómic celebrado en la Facultad de Filosofía y Letras de la Universidad de Zaragoza los días cuatro, cinco y seis de abril de 2017. Dicho evento generó un punto de inflexión, un antes y un después, en los estudios sobre cómic. Nunca antes se habían encontrado tal cantidad de expertos en el tema mediante un foro público, el cual tuvo una trascendencia académica notoria en el ámbito nacional e internacional. Como muestra de este fructífero encuentro nació esta publicación, la cual está estructurada en cinco grandes bloques: lenguaje, estudios históricos, prisma de género y LGTBI; humor gráfico, cómic y

1 Gracia, J. y Asion, A. (coords.), Nuevas visiones sobre el cómic. Un enfoque interdisciplinar, Zaragoza, Prensas de la Universidad de Zaragoza, 2018. 
periodismo; didáctica y educación; manga e influencia japonesa y relaciones con otras artes. Además y para contextualizar el producto, dicha obra consta de una introducción realizada por los coordinadores Julio A. Gracia Lana y Ana Asión Suñer, esbozándose así las pretensiones, objetivos y metas que tenía dicho congreso y, por ende, esta publicación.

Aparte de estos cinco grandes bloques articulados a través de escritos breves de importante índole, hay tres artículos que tienen la función de actuar como apertura de dicha obra. Estos textos presentan una enorme rigurosidad y calidad científica, siendo realizados por figuras de significativo renombre en algunos de los campos de investigación que componen el nutrido mundo académico del cómic. En primer lugar, se nos presenta «Cincuenta años críticos» de Antonio Altarriba Ordóñez (Zaragoza, 1952), catedrático de literatura francesa en la Universidad de País Vasco, novelista, ensayista, crítico y guionista de cómic. Además, ha sido una figura fundamental para el desarrollo de los estudios sobre cómic, inaugurando en los años ochenta el primer número de la revista Neuróptica; promoviendo así la ruptura con la academia clásica para insertar la historieta como un camino más dentro de la investigación científica. A continuación se sitúa «Educación, literatura y manga: homenaje a Jirō Taniguchi (1947-2017) y La época de Botchan», realizado por V. David Almazán Tomás (Zaragoza, 1971), profesor en el Departamento de Historia del Arte de la Universidad de Zaragoza. Antropólogo, historiador del arte y especialista en cultura japonesa. Sus investigaciones más punteras están centradas en las manifestaciones artísticas niponas y concretamente en el mundo del grabado ukiyo-e. Se denota con este artículo la rigurosidad científica con la que pueden realizarse los textos relativos al manga nipón, un producto exclusivo del País del Sol Naciente. Por último y como colofón de esta introducción tenemos «Viñetas para la exhibición de atrocidades. Memorias del horror» de Juan Carlos Pérez García (Málaga, 1969). Conocido por su sobrenombre «Pepo Pérez» es licenciado en derecho y profesor en la Universidad de Málaga, además de crítico y dibujante de cómic. Ha realizado obras tan importantes como El Vecino, ${ }^{2}$ producida junto a Santiago García para Astiberri Ediciones. Como podemos ver, es muy difícil superar una introducción que nos recoja a intelectuales de este calibre, lo cual hace más atractiva esta publicación. Si hacemos el compendio de todas las secciones que componen esta obra, nos daremos cuenta de que es una publicación pulcra, bien articulada y, ante todo,

2 Garcia, S. y Perez, J. C., El Vecino, Bilbao, Astiberri Ediciones, 2004. 
atractiva. Se consagra así como un referente dentro del joven pero pujante mundo de la investigación en lo que a la historieta se refiere.

Como conclusión, podemos afirmar que el libro ha tenido una buena acogida en el mercado editorial. Esto es debido a su carácter interdisciplinar, su característica más sobresaliente y diferenciadora. Siendo este un testimonio de la riqueza cultural que tiene nuestro país en este campo de estudio. Gracias a este tipo de publicaciones se obtiene una panorámica amplia del mundo del cómic y de cómo todos sus fragmentos conforman una maquinaria compleja, eficiente y sobre todo productiva. Tanto es así que este presente año 2019, y debido al éxito del anterior foro, se ha celebrado en la Universidad de Zaragoza los días quince, dieciséis y diecisiete de mayo la segunda edición del Congreso Internacional de Estudios Interdisciplinares sobre Cómic. El cual dará una vez más otra publicación de esta índole, que proporcionará, sin lugar a dudas, una importante visibilidad a las diversas investigaciones que están en marcha en la actualidad, no solo en nuestro país, sino en el marco internacional. La Universidad de Zaragoza se consolida así como un lugar indispensable para cualquier intelectual que quiera investigar, aproximarse y apreciar desde el ámbito académico, editorial y artístico, el mundo de la historieta y sus múltiples posibilidades. 